\title{
STRATEGI SENIMAN KALIGRAFI DALAM MENGIKUTI LOMBA HIASAN MUSHAF DI KOTA PALANGKA RAYA
}

\author{
Dr. Asep Solikhin, M.A* \\ Nuraida Rahmi* \\ Universitas Muhammadiyah Palangkaraya \\ asepsolikhin@umpalangkaraya.ac.id, nuraidarahmi@gmail.com
}

\begin{abstract}
Calligraphy or commonly known as khath is one of Islamic art which received great attention from the Muslim community, not least the Muslims in the city of Palangkaraya. In fact, the calligraphy is used as one of the branches that are contested in Musabaqah Tilawatil Qur'an (MTQ), namely Musabaqah Khattil Qur'an (MKQ). In MKQ divided into three (3) groups: group branches manuscript, ornamentations and decor. The ability of the artists of calligraphy in making ornamentations at the time of the race, would have a different strategy with the aim that the resulting work better and can be categorized as the best.

Subject (source data) in this study consists of three (3) artists, calligraphy, calligraphic artist group three are ornamentations with a proven record in the race making ornamentations.

The results showed that: first, the most supportive factor in implementing strategies make decorations Manuscripts at the time of the race, there are two (2) factors: (a) Factors Psychic (Soul), which strengthen the spiritual self to God; (B) Physical factors (Physical), ie prior to the start of the race and to consume nutritious foods and regular breaks; second, the difficulties encountered in making the calligraphy artist ornamentations at the time of the race was the lack of preparation, drafting difficulties paragraph, and difficulties in the manufacture of trim and motifs.
\end{abstract}

Keyword : strategy, calligraphy artists, manuscript adornment

\section{A. LATAR BELAKANG}

Kaligrafi atau biasa dikenal khathtumbuh dan berkembang dalam budaya Islam menjadi alternatif ekspresi menarik yang mengandung unsur penyatu yang kuat. Kaligrafi berkembang pesat dalam kebudayaan Islam adalah:pertama,karena keunikan dan kelenturan huruf-huruf Arab. Khath sendiri sebagai satu bentuk kesenian yang memiliki aturan yang khas, telah tumbuh secara lepas maupun terpadukan dalam bagian-bagian unsur bangunan yang mempunyai makna keindahan tersendiri. Salah satu fakta yang mempesona dalam sejarah seni dan budaya Islam adalah keberhasilan bangsa Arab,Persia,Turki dan India dalam menciptakan bentuk-bentuk dan gaya tulisan kaligrafis keberbagai jenis variasi,antara lain: Kufi, Riq'ah,Diwani,Tsuluts, Naskhi dan lain-lain. ${ }^{1}$

\footnotetext{
${ }^{1}$ http://wordskripsi.blogspot.com/2010/03/carapemesanan.html
} 
Para ulama, satrawan, teknokrat, dan lainnya mengakui bahwa Al-Qur'an memang luar biasa dan indah. Keindahan Al-Qur'an itu tak hanya terletak pada isi kandungannya atau pada seni membaca, namun juga pada seni tulisnya yang dikenal dengan nama khatt atau kaligrafi.

Muhammad Ibnan Syarif berpendapat bahwa :

Kaligrafi sebagai seni suci,karena dengan kaligrafi inilah Al-Qur'an yang merupakan wahyu Allah ditulis dan diteruskankepada manusia mewarnai kehidupan dalam dunia seni rupaIslam. ${ }^{2}$

Tradisi menulis kaligrafi bermula sejak Nabi Muhammad SAW menugaskan sahabatsahabatnya untuk menulis dan menghafal Al-Qur'an. Tulisan-tulisan Al-Qur'an kemudian disusun sebagai mushaf pada masa Khalifah Utsman bin Affan (644-656 M). Menulis kaligrafi atau menyalin AlQur'an kemudian berkembang sebagai tradisi dan menyebar keberbagai negara bersamaan dengan meluasnya agama Islam.

Indonesia sebagai Negara mayoritas muslim juga tidak lepas dalam mempelajari seni Islam yaitu kaligrafi. Perkembangan kaligrafi semakin semarak sejak dijadikan

${ }^{2}$ Syarif Muh Ibnan, ketika Mushab Menjadi

Indah, Semarang: 2003, Cet. Ke-I, h.2 salah satu cabang yang dilombakan dalam MusabaqahTilawatil Qur'an (MTQ) dari tingkat nasional sampai ke daerah yang tersebar di seluruh Indonesia. Cabang yang diberi nama Musabaqah Khattil Qur'an (MKQ) ini selain menarik minat, juga berhasil membibitkan kader-kader penulis dan pelukis kaligrafi dari sekolah, pesantren, bahkan perguruan tinggi. Dari sejumlah peserta MKQ yang menyebar diberbagai daerah, muncul ahli bidang penulisan naskah, hiasan mushaf, dan dekorasi yang dikompetisikan. ${ }^{3}$ Keindahan tulisan mushaf dengan perpaduan warna dan kelincahan tangan dalam menggoreskan kalam (pena) yang menghiasi naskah (khat) menjadikan para seniman kaligrafi berlomba-lomba untuk menciptakan hasil yang lebih baik dan indah. Untuk memiliki kemampuan dalam menulis seni kaligrafi mushaf tentunya tidak mudah secara langsung mampu membuatnya, tetapi dengan cara belajar terus-menerus karena belajar dianggap sebagai proses perubahan prilaku sebagai akibat dari pengalaman dan latihan.

Hilgard mengungkapkan bahwa :

Belajar adalah :"Learning is the prosess by wich an activity originates or changed through training prosedurs(wather in the

\footnotetext{
${ }^{3}$ H.D.Sirojuddin.AR,Pengantar Kuliah Seni Islam, Jakarta: Fakultas Adab dan Humaniora UIN Syarif Hidayatullah, 2004, h.37.
} 
laboratory or in the natural environment) as distinguished from changes by factors not attributable to training." Bagi Hilgard, belajar itu adalah proses perubahan melalui kegiatan atau prosedur latihan baik latihan di dalam laboratorium maupun dalam lingkungan alamiah. ${ }^{4}$

Di samping itu juga, belajar membuat hiasan mushaf diperlukannya sebuah strategi dengan tujuan agar hiasan mushaf yang dihasilkan lebih baik dalam menghiasi naskah Al-Qur'an.

Menurut pengamatan yang penulis lakukan, dalam penyelenggaraan MTQ yang diselenggarakan di kota Palangka Raya, bahwa sekian banyaknya peserta MKQ memiliki kemampuan yang sama dalam pembuatan kaligrafi mushaf. Namun, dari hasil penilaian dewan hakim (juri) hanya ada beberapa yang dapatdikategorikan layak untuk menjadi yang terbaik. Menurut penulis, hasil karya yang baik tentu para seniman kaligrafi memiliki masing-masing strategi dalam pembuatan kaligrafi mushaf agar karya yang dihasilkan terlihat lebih baik dan indah, baik dari segi perpaduan warna yang dikombinasikan, pengukuran dalam penempatan naskah, maupun cara

\footnotetext{
${ }^{4}$ Wina Sanjaya, Strategi Pembelajaran Berorientasi Standar Proses Pendidikan, Jakarta: Prenada Media, 2011, Cet.8, h. 112.
}

menggoreskan pena (kalam) dan faktor pendukung lainnya.

Adapun dasar dari penelitian ini adalah untuk mengetahui teknik apa saja yang digunakan para seniman kaligrafi dalam membuat hiasan mushaf pada saat lomba sehingga menjadi penilaian yang berbeda dengan seniman lainnya. Maka mampu memberikan kontribusi yang positif untuk memajukan UniversitasMuhammadiyah Palangka Rayasecara umum terlebih khusus bagi Fakultas Agama Islam (FAI) ProgramStudi Pendidikan Agama Islam. Karena kaligrafi merupakan peninggalan peradaban seni budaya Islam yang hingga saat ini masih terjaga dan terus berkembang. Dalam membuat kaligrafi mushaf yang dipelajari tidak hanya menghias mushafnya saja, namun juga harus mampu membuat tulisan (khatt) baik khattNaskhi, Tsulus, Kufi, Riq'ah, Farisi, Diwani, maupun Diwani Jali.

\section{B. Pengertian Kaligrafi}

Ungkapan kaligrafi (dari bahasa inggris yang disederhanakan, calligraphy) diambil dari kata "kalios" yang berarti indah dan graph yang berarti tulisan atau aksara. Arti seutuhnya kata "kaligrafi" adalah kepandaian menulis elok, atau tulisan elok. Bahasa Arab sendiri menyebutnya khat yang berarti garis atau tulisan indah. 
Definisi lebih lengkap dikemukakan oleh Syeikh Syamsudin Al Akfani di dalam kitabnya "Irsyad Al Qasid", bab "Hars Al 'ulum" sebagai berikut :

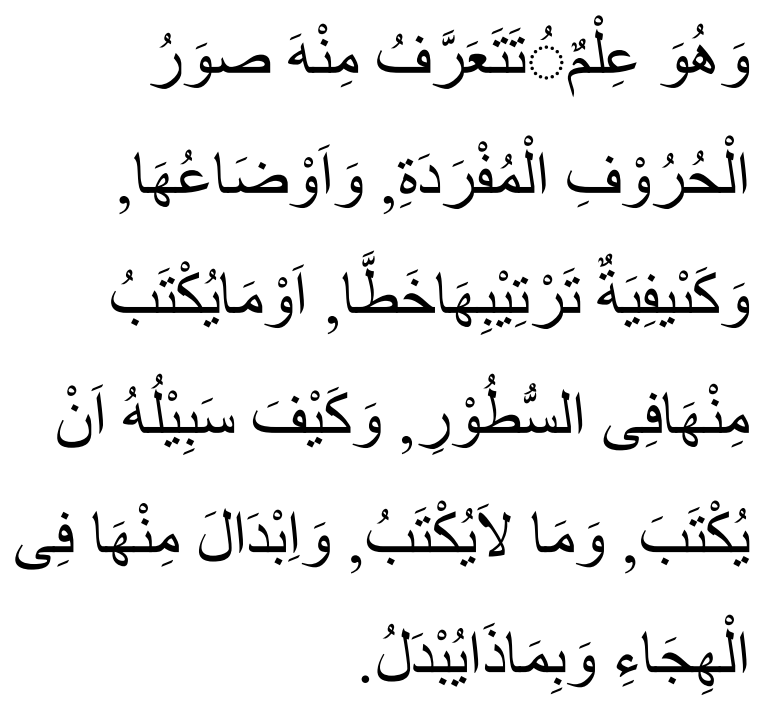

Artinya:

"khat/kaligrafi adalah suatu ilmu yang memperkenalkan bentuk-bentuk huruf tunggal,letak-letaknya dan cara-cara merangkainya menjadi sebuah tulisan yang bersusun. Atau apa-apa yang ditulis diatas garis, bagaimana cara menulisnya dan menentukan mana yang tidak perlu ditulis; bagaimana cara menulisnya dan menentukan mana yang tidak perlu ditulis; mengubah ejaan yang perlu diubah dan menentukan cara bagaimana untuk mengubahnya."

${ }^{5}$ D. Sirojuddin AR, SeniKaligrafiIslam (edisikedua), Jakarta : PT. Remaja SRosdakarya, 2000, h. 3
Definisi lain dari Yakut Al Musta'simi, kaligrafer kenamaan di masa kesultanan Turki Utsmani (Ottoman) melihat seni kaligrafi dari sudut keindahan yang dikandungnya. Karena itu, ia membuat batasan sebagai berikut :

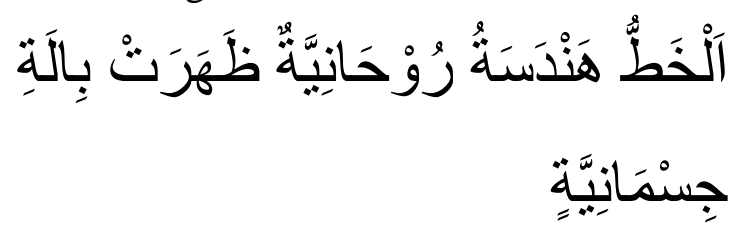

Artinya :

"kaligrafi adalah seni arsitektur rohani yang lahir melalui perabot kebendaan."

\section{Jenis-jenis Khath dalam penulisan}

\section{Kaligrafi}

Drs. Abdul Karim Husain dalam bukunya Khath Seni Kaligrafi yang dikutif dari C. Israr dalam bukunya Dari Teks Klasik Sampai ke Kaligrafi Arab memberikan contoh jenis-jenis khath tersebut dalam setiap penjelasannya. Adapun jenis khath arab yang lebih dikenal dan banyak dipergunakan sampai sekarang, ialah: ${ }^{6}$

1. Khath Tsulus

Dinamakan khath Tsulus karena ditulis dengan kalam atau pulpen yang ujung pelatuknya dipotong dengan ukuran

\footnotetext{
${ }^{6}$ Israr. C, Dari Teks Klasik Sampai Ke Kaligrafi Arab, Jakarta: Darul Ulum Press, 1985, Cet. Ke-I. H.79
} 
sepertiga (tsulus) goresan kalam. Adapun yang menamakannya "khath Arab" karena gaya ini merupakan sumber pokok aneka ragam kaligrafi Arab yang banyak jumlahnya sesudah khath Kufi.

Khath tsulus lebih bersifat monumental, dipakai terutama untuk tujuan-tujuan dekorasi pada berbagai manuskrip dan inskripsi-inskripsi, sebagaimana sekarang banyak dipakai untuk menghias temboktembok, gedung, penulisan mushaf alQur'an (sampul depannya), untuk judul, nama kitab dan untuk hiasan lainnya.

\section{2. $\quad$ Khath Naskhi}

Khath Naskhi yang disebut juga khath Nasakh, telah disempurnakan dengan bentuk yang indah oleh ahli kaligrafi Arab termasyhur, Al-Wazir Abu Ali Muhammad Ibnu Muqlah dan saudaranya Abu Abdullah Al-Hasan yang wafat dalam tahun 338 Hijriyah. Keduanya telah menciptakan kaidah dan aturan khath Naskhi dengan menentukan ukuran panjang pendek dan jarak huruf, serta gaya dan iramanya dengan rapi sekali.

Rumus-rumus yang digunakan dalam penulisan khath Naskhi, menurut Tarikh Klasik Islam, sama dengan yang digunakkan untuk khath Tsulus, dengan standar empat atau lima titik untuk Alif.Persamaan jarak bagi setiap huruf Naskhi dengan Tsulus, menurut Al-Ustadz Mahmud Yazir (Turki), adalah karena akrabnya bentuk Naskhi kepada Tsulus.

\section{Khath Farisi}

Sebagai warisan nenek moyang mereka bangsa Saman, bangsa Iran menulis dengan khath Pahlevi. Gaya kaligrafi ini merupakan nisbah ke Pahle, suatu kawasan antara Hamadan, Isfahan, dan Azerbaijan.

Saat islam menaklukkan negeri Persia, masyarakat Iran pun memeluk Islam sebagai agama baru mereka. Melalui pergaulan dengan masyarakat Arab muslim, orangorang Iran mengganti tulisan Pahlevi dengan tulisan Arab yang kemudian mereka namakan dengan sebutan Khath Ta'liq. Pada waktu-waktu selanjutnya, lahir pula gayagaya khatt lain seperti Nasta'liq dan Syikasteh. Terutama dua tulisan pertama, kerap disebut Farisi saja karena mengingat asal usulnya dari Persia.

4. $\quad$ Khath Diwani

Diwani adalah salah satu khath yang diciptakan oleh Turki Utsmani. Peletak dasar-dasar kaidah dan ukuran hurufhurufnya adalah Ibrahim Munif. Tulisan ini mulai populer setelah penaklukan kota konstatinopel oleh sultan Usmani Muhammad Al-Fatih tahun $875 \mathrm{H}$.

Penamaannya dengan Diwani adalah nisbah kepada kantor-kantor (diwan) pemerintah 
dimana tulisan tersebut digunakan dan dari dewan-dewan pemerintahan itulah khath ini menyebar keseluruh kalangan masyarakat.

Semula diwani diciptakan untuk menyalin berbagai ketetapan, dokumen, dan bukubuku resmi Negara. Di zaman modern, gaya kaligrafi ini berfungsi sebagai alat dekorasi. $^{7}$

\section{5. $\quad$ Khath Diwani Jali}

Khath Diwani Jali merupakan salah satu gaya kaligrafi yang dibuat oleh masyarakat Turki Usmani hasil olahan kaligrafer besar Syahlan Pasha. Gaya ini dianggap sebagai hasil pengembangan dari khath Diwani atau diwani "adi (biasa). Jail artinya "jelas" (wadih), maksudnya "sangat jelas karena detail-detail syakal di dalamnya”.

Tujuan diciptakannya Diwani Jali adalah untuk menuliskan peraturan-peraturan kesultanan dan surat-surat ke luar negeri. ${ }^{8}$

\section{Khath Kufi}

Prototip atau bentuk awal dari khath Kufi sudah ada semenjak masa sebelum Islam, dengan bentuk hurufnya yang muraba'ah atau bersegi. Pada zaman khalifah Ali bin Abi Thalib ibu kota Pemerintahan dipindahkan dari Madinah ke Kufah. Pada masa itulah para ahli khath di kota tersebut banyak mempergunakan khath Muraba'ah, serta menyempurnakan dan

${ }^{7}$ D.Sirajuddin AR, Koleksi Karya Master Kaligrafi Islam, Jakarta: 2007, h. 177

${ }^{8}$ Ibid, h. 178 mengembangkanya sehingga kemudian khath tersebut dikenal dengan nama khath Kufi.

\section{Khath Riq'ah}

Jenis khath Riq'ah yang disebut juga khath Riq'ie adalah tulisan arab yang dapat ditulis dengan cepat, mendekati kecepatan stenografi. Oleh sebab itu, khath riq'ah ini banyak dipergunakan dalam lingkungan perguruan tinggi Islam seperti Universitas al-azhar dan darul Ulum Kairo, demikian juga pada berbagai madrasah. Para dosen dan mahasiswa dalam kegiatan kuliahnya kebanyakan mempergunakan khath riq'ah.

\section{Laporan Hasil Penelitian dan Pembahasan}

Pada pelaksanaan penelitian yang penulis lakukan dari hasil observasi, wawancara serta diadakannya praktek langsung dalam membuat hiasan mushaf oleh subjek, dengan tujuan agar memperkuat kevalidan data yang didapat bahwa penelitian ini benar-benar dilakukan. Maka dapat penulis uraikan sebagai berikut:

\section{Faktor yang mendukung dalam} membuat hiasan mushaf saat lomba

Dalam orientasi membuat hiasan mushaf di saat lomba, tentu ada faktor-faktor yang mendukung baik dari faktor psikis (kejiwaan) dan faktor fisik (Jasmani). Mental dan jasmani merupakan satu 
kesatuan yang seharusnya diselaraskan dalam setiap fungsinya.

Pada pembahasan ini, penulis akan memaparkan kedua faktor tersebut melalui pernyataan-pernyataan kedua subjek dari hasil wawancara serta dilakukannya praktek dalam membuat hiasan mushaf. Tujuannya adalah, agar apa yang disampaikan dari hasil observasi dan wawancara serta didukung dengan dilakukannya praktek secara langsung, maka penulis lebih mudah menjabarkannya dalam penelitian ini.

a) Faktor apa saja yang paling mendukung dalam membuat hiasan mushaf pada saat lomba dari segi psikis (mental) ?

Dari hasil wawancara, menurut AM faktor psikis yang mendukung dalam membuat hiasan mushaf di saat lomba yaitu:

"Karena kita orang muslim, intinya dari segi ibadah harus diutamakan dan dijaga juga kesucian lahir dan bathin, puasa senin dan kamis dan juga ditambah dengan shalat hajat dan shalat sunat lainnya". 9

Dari pernyataan WD mengenai faktor psikis yaitu:

"Dukungan orang-orang terdekat terutama orang tua dan guru yang mengajarkan, mental yang kuat, percaya diri, niat yang

${ }^{9}$ Wawancara dengan AM di Sanggar Kaligrafi AnNuun Palangka Raya, 13 Maret 2014 benar-benar karena Allah SWT, dan suasana hati yang nyaman dan tenang". ${ }^{10}$

Adapun menurut subjek FR faktor pendukungnya adalah;

"Menurut saya faktor pendukung secara psikis pada saat lomba itu adalah yang pertama sekali adalah semangat. Karena seniman mushaf itu sendiri bertanding itu nantinya akan dinilai, maka yang paling pertama itu adalah semangat, mental juara dan yakin bahwa kita menang. Tidak lupa juga pada saat sebelum lomba itu kita harus berdo'a, harus menjaga hati, tenang secara fikiran. Kita harus tenang, harus siap mental dulu pada saat bertanding". ${ }^{11}$

Jadi, dapat disimpulkan bahwa faktor yang mendukung dari faktor psikis yaitu menjaga kesucian lahir dan bathin, menjaga ibadah yang wajib disertai ibadah yang sunah, memiliki mental yang kuat serta semangat yang tinggi untuk meraih juara, menjaga kondisi hati yang nyaman dan tenang agar pada saat lomba bisa diikuti dengan stabil. Dan yang lebih penting adalah dukungan orang-orang sekitar.

b) Faktor apa saja yang paling mendukung dalam membuat hiasan mushaf di saat lomba dari faktor fisik?

\footnotetext{
${ }^{10}$ Wawancara dengan WD di Sanggar Kaligrafi AnNuun Palanka Raya, 16 Februari '14

${ }^{11}$ Wawancara dengan FR di LPTQ Prov. KalTeng, 29 Mei 2014
} 
Adapun pernyataan AM dari hasil wawancara mengenai faktor fisik, sebagai faktor pendukung dalam menghadapi lomba: "Kalau faktor fisik, atau kesehatan, kalau kita sering bagadang atau tidur larut malam paling ngak dikurangin, terus asupan makanan dan minuman harus dijaga yaitu empat sehat lima sempurna". ${ }^{12}$

Pernyataan yang sama dari WD dari faktor fisik yaitu:

"benar-benar dalam keadaan sehat karena lombanya benar-benar memerlukan waktu yang tidak singkat". ${ }^{13}$

Adapun faktor fisik yang FR lakukan dalam kegiatan menghadapi lomba:

"Okke,, secara fisik faktor pendukungnya adalah yaitu kita harus menjaga kesehatan karena kondisi yang prima akan menghasilkan sebuah karya yang juga sangat maksimal. Karena paling tidak kita yaa, sebelum saat menjaga kesehatan itu kita harus menjaga pola makan, tidak boleh begadang, kemudian kita harus kapan perlu minum suplemen makanan supaya kesehatan kita tetap terjaga tentunya. Dan juga harus

\footnotetext{
${ }^{12}$ Wawancara dengan AM di Sanggar Kaligrafi AnNuun Palangka Raya, 13 Maret 2014

${ }^{13}$ Wawancara dengan WD di Sanggar kaligrafi AnNuun Palangka Raya, 16 Februari 2014
}

tetap berolah raga yang pada intinya jaga kesehatan ajalah". 14

Dapat disimpulkan dari pernyataan ketiganya, bahwa faktor fisik yang harus dijaga pada saat lomba hiasan mushaf yaitu menjaga kesehatan dengan istirahat dan pola makan yang teratur, olah raga, minum suplemen makanan.

\section{Teknik Seniman Kaligrafi dalam} Membuat Hiasan Mushaf di Saat Lomba

a) Apa saja persiapan yang harus anda lakukan dalam membuat hiasan mushaf pada saat lomba?

Adapun persiapan yang dilakukan dalam membuat hiasan mushaf di saat lomba, menurut AM yaitu:

"Menurut saya setiap orang memiliki cara yang berbeda-beda, namun pada dasarnya tujuannya sama, kalau saya mencakup empat hal: yaitu orangnya, baik dari kejiwaannya, tinta; yang pastinya yang hitam yang digunakan, kalau dari segi merk terserah bagaimana yang menurut anda enak untuk menggunakannya, kalam/pena atau yang sering disebut handam, dan ini mudah saja di dapat, baik dari bambu, kayu atau juga dari logam mata penanya, dan yang terakhir

\footnotetext{
${ }^{14}$ Wawancara dengan FR di gedung LPTQ sesaat sebelum MTQ Nasional XXV di Batam 2014, 29 Mei 2014
} 
yaitu media; kalau untuk hiasan mushaf biasanya kertas putih manila". 15

Adapun pernyataan WD tentang persiapan dalam membuat hiasan mushaf adalah:

"Yang pertama itu latihan menulis kaligrafi, membuat desain, mengatur warna desain, membuat maal dan mengatur waktu". ${ }^{16}$

Adapun yang dimaksudkan WD dari pernyataannya tentang persiapan dalam membuat hiasan mushaf adalah:

1) Latihan

2) Membuat Desain

3) Mengatur Warna

4) Membuat maal

5) Mengatur Waktu

Menurut subjek FR persiapannya adalah:

"kalau persiapannya ya benar-benar harus siap dari segi fisik maupun dari segi mental. Adapun persiapan-persiapan sebelum lomba itu biasanya kita ada waktu tertentu yang digunakan untuk persiapan yaitu TC atau pelatihan. Nah,,,dalam pelatihan itu kita memanfaatkan untuk mempersiapkan strategi juga yaitu dalam hal pembuatan desain, pengoplosan warna, kemudian

\footnotetext{
${ }^{15}$ Wawancara dengan AM di Sanggar Kaligrafi AnNuun Palangka Raya, 13 Maret 2014

${ }^{16}$ Wawancara dengan WD di Sanggar Kaligrafi AnNuun Palangka Raya,
}

menyiapkan alat-alat kaligrafi itu benarbenar harus disiapkan secara matang". ${ }^{17}$

Adapun yang dimaksudkan subjek FR mengenai persiapan dalam membuat hiasan mushaf yaitu:

1) Persiapan fisik dan mental: dalam hal ini sebagai seseorang yang ingin mengikuti ajang perlombaan benar-benar harus menjaga kesehatan baik kesehatan jasmani maupun kesehatan rohani.

2) Training Center (TC) atau pelatihan; tujuannya yaitu untuk mempersiapkan desain, maal, tata warna, ornamen, serta untuk menyiapkan alat-alat penunjang seperti kuas, tinta, handam, dsb.

Dari hasil wawancara yang dilakukan dari subjek AM, WD, dan FR maka dapat disimpulkan bahwa persiapan dalam membuat hiasan mushaf yaitu peralatan yang lengkap, latihan yang terus-menerus, membuat desain serta yang terpenting adalah mempraktekkannya terlebih dahulu, dengan tujuan untuk mengatur durasi waktu.

b) Apa saja perlengkapan yang disiapkan dalam membuat hiasan mushaf di saat lomba?

Adapun pernyataan dari subjek AM dari hasil wawancara yang penulis lakukan, perlengkapan yang harus disiapkan yaitu:

\footnotetext{
${ }^{17}$ Wawancara dengan FR di gedung LPTQ KalTeng pada saat pembinaan menuju MTQ Nasional Batam 2014, 29 Mei 2014
} 
"Menurut saya, kalau dari perlengkapan yang pasti kita menyiapkan peralatan seperti pensil, penanya, penghapus juga perlu, tinta, cat yang warna-warni yang telah kita polos sehingga ada warna terang gelapnya, kemudian menyiapkan malnya atau cetakan untuk ditempatkan di media yang kosong agar memudahkan kita dalam mengerjakannya". 18

Dari penjelasan subjek AM bahwa perlengkapan yang perlu disiapkan yaitu:

1) Pensil;

2) Pena;

3) Tinta;

4) Cat warna-warni;

5) Mal;

Pada gambar tersebut terlihat jelas bahwa dalam membuat mal perlu kreativitas, keuletan dan kesabaran. Motif-motif hiasan mushaf sangatlah kecil dan perlu kehatian dalam membuatnya. Adapun cara dalam membuat mal, dapat penulis gambarkan dari hasil praktek dengan AM yaitu:

1) Buatlah gambar mushaf di karton yang kosong dengan pensil, gambar desain atau motif dapat diambil dari mushafmushaf yang sudah jadi atau hasil karya MTQ terbaru yang dipadukan dengan pemikiran sendiri.

\footnotetext{
${ }^{18}$ Wawancara dengan AM di gedung LPTQ Kalteng pada saat pembinaan menuju MTQ Nasional Batam 2014, 29 Mei 2014
}

2) Selanjutnya, potonglah gambar tersebut dengan hati-hati dengan memotong bagian tengahnya menggunakan alat kater atau alat lainnya. Ini adalah cara singkat yang penulis paparkan dalam membuat mal hiasan mushaf dari hasil praktek dengan subjek AM ketika mempraktekkan membuat mal sebelum mempraktekkan membuat hiasan mushaf.

Adapun pernyataan dari WD, dari hasil wawancara yang penulis lakukan, bahwa perlengkapan yang harus disiapkan yaitu:

"Menurut saya biasanya perlengkapan yang digunakan tinta, handam yang digunakan dari bambu, kemudian karton, pewarna, penghapus, penggaris, mal motif",19

Adapun perlengkapan yang dimaksudkan WD yaitu:

1) Tinta;

2) Handam;

3) Pewarna;

4) Alat pendukung lainnya seperti pensil, penghapus, penggaris, dll.

5) mal;

Adapun pernyataan FR saat wawancara, peralatan yang harus disiapkan yaitu; "perlengkapan-perlengkapan itu ya dari alat sendiri itu kita harus mempersiapkan alat-

\footnotetext{
${ }^{19}$ Wawancara dengan WD di Sanggar kaligrafi AnNuun Palangkaraya, 14 Maret 2014
} 
alat tulis kaligrafi seperti handam, tinta, penghapus, pensil juga. Kemudian kita juga harus mempersiapkan mal kemudian alatalat pendukung lainnya bawa ember, bawa tabung, bawa lap juga itu salah satu hal pendukung juga dalam persiapan lomba". ${ }^{20}$

Jadi dapat disimpulkan bahwa peralatan/perlengkapan yang harus disiapkan dalam membuat hiasan mushaf yaitu seperti cat, pensil, penghapus, penggaris, tinta hitam, handam, mal dan alat-alat pendukung lainnya seperti ember, serbet, serta tabung.

\section{c) Strategi seniman kaligrafi dalam membuat hiasan mushaf pada saat lomba}

Adapun strategi yang dimiliki AM, dari hasil wawancara dengan penulis yaitu:

"Kalau strategi saya kita harus memahami kriteria yang disukai dewan hakim, biasanyakan selera orang beda-beda. Katanya: "aku suka warna merah". Otomatis kita memahami dia kan untuk menggunakan warna merah. Kemudian yang satunya aku suka tulisan yang seperti ini, paling gak kita rangkum dan kita masuki satu persatu dan juga kita tambah dengan pemikiran kita. Terus juga persiapan kita harus matang, intinya kita harus latihan sebelum

\footnotetext{
${ }^{20}$ Wawancara dengan FR di gedung LPTQ pada saat pembinaan menuju MTQ Nasional Batam 2014, 29 Mei 2014
}

menghadapi lomba, satu Minggu, dua Minggu, satu bulam atau beberapa bulan sebelum menghadapi lomba. Intinya kalau kita ingin lebih baik, maka latihannya harus lebih banyak juga persiapan kita harus matang, dari segi mental otomatis kita tidak masalah". 21

Adapun strategi yang digunakan WD dari pernyataannya dengan penulis melalui wawancara yaitu:

"Biasanya itu di tulisan, tulisan harus di mantapkan. Latihan menulis terus-menerus agar pada saat bertanding tidak gugup". ${ }^{22}$

Adapun yang dimaksudkan WD, bahwa strategi yang digunakan pada saat lomba yaitu lebih mengutamakan kaidah tulisan yaitu dengan latihan menulis terus menerus sebab penilaian tertinggi adalah pada tulisan khatnya. Sehingga WD lebih menekankan kepada kaidah penulisannya agar hasil yang dibuat lebih baik.

Adapun pernyataan FR pada saat wawancara dengan penulis mengenai strategi ini yaitu:

"Adapun strategi saya pada saat mengikuti lomba hiasan mushaf ini yaitu yang pertama sekali harus benar-benar mempersiapkan diri secara fisik dan mental. Kemudian kita harus tau seperti apa selera dewan juri itu

\footnotetext{
${ }^{21}$ Wawancara dengan AM di gedung LPTQ KalTeng pada saat pembinaan menuju MTQ Nasional Batam 2014, 29 Mei 2014

${ }^{22}$ Wawancara dengan WD di sanggar kaligrafi anNuun Palangka raya, 14 Maret 2014
} 
seperti apa gitu. Misalkan juri itu suka warna ini, juri itu suka motif yang seperti ini atau mungkin desain terbarunya seperti apa salah satu strateginya. Kita harus mempersiapkan desain tata warna itu yang terbaru yang modern. Kemudian strategi selanjutnya yaitu pada saat lomba itu kita harus berpacu dengan waktu kita harus mampu memanaj waktu itu dengan baik karena kalau kita bisa memenej waktu dengan baik dengan secara disiplin juga maka nanti hasilnya juga akan maksimal. Kemudian strategi selanjutnya ya paling tidak kita harus memppersiapkan diri. Harus mengikuti pelatihan atau pemusatan latihan itu secara maksimal. Karena dalam pemusatan latihan itu kita benar-benar terkontrol. Paling tidak pada saat pelatihan itu kita harus punya karya satu atau dua karya jadi. Yang mana karya itu pada saat pembuatan karya itu kita di try out jadi seperti sudah tampil. Jadi sehingga kita mampu pada saat lomba kita itu bisa memperkirakan waktu itu tepat waktu jadi intinya seperti itu". 23

\section{DAFTAR PUSTAKA}

Abdul Qadir, Metodologi Riset Panduan Dasar Melakukan Penelitian Ilmiah, Palangka Raya, tanpa penerbit, 1999.

\footnotetext{
${ }^{23}$ Wawancara dengan FR di gedung LPTQ KalTeng pada saat pembinaan menuju MTQ Nasional Batam 2014, 29 mei 2014
}

Boby Es-Syawal El-Iskandar, Ragam Hiasan Mushaf Nusantara: Panduan Teknik Pengolahan Hiasan Mushaf (Untuk Kebutuhan MTQ), Jakarta: PT. Balemedia, 2003, Cet.I

Departemen Pendidikan Nasional, Kamus Besar Bahasa Indonesia, Jakarta: PT. (Persero) Penerbitan dan Percetakan Balai Pustaka, 2005, Cet. 3.

D. Sirajudin AR, Pengantar Kuliah Seni Islam (Diskusi Tarikh, Tokoh dan Alisan), Jakarta: Fakultas Adab dan Humainiora UIN Syarif Hidayatullah, 2004.

D. Sirajudin AR, Koleksi Karya Master Kaligrafi Islam, Jakarta: 2007.

Elisabeth Christine Yuwono, Pengaruh Kaligrafi dalam Desain Logotype, Surabaya: Nirmana, 2005.

Fauzi Salim Afifi, Cara Mengajar Kaligrafi

(Pedoman Guru), Jakarta: DarulUlum Press, 2002, Cet.I.

Israr. C, Dari Teks Klasik Sampai Ke Kaligrafi Arab, Jakarta: 1985, Cet. I.

Lexy J. Moulang, Metodologi penelitian kualitatif, $\mathrm{Ba} \quad \Gamma$. Remaja Rosdakarya, 21

Mahmud Yunus, Kc ו-Indonesia, Jakarta: PT. Mahmud Yunus Wadzurriyah, 1972.

Nasution, Metode Research (Penelitian Ilmiah), Jakarta: PT. BumiAksara, 2004.

Sadjiman Ebdi Sanyoto, Dasar-Dasar Tata Rupa dan Desain (Nirmana), Yogyakarta: CV. Arti Bumi Intaran, Cet I, 2005. 
Sugiyono, Memahami Penelitian Kualitatif, Bandung: CV. Alfabeta, 2010.

Suharsimi Arikunto, Manajemen Penelitian, Jakarta: PT. RinekaCipta, 2003.

Suharsimi Arikunto, Prosedur Penelitian Suatu Pendekatan Praktek Edisi Revisi VI, Jakarta: PT. Rineka Cipta, 2006.

Syarif Muh Ibnan, Ketika Mushab Menjadi Indah, Semarang: 2003, Cet. I.

WinaSanjaya, Strategi Pembelajaran Berorientasi Standar Proses Pendidikan, Jakarta: Prenada Media, 2011, Cet 8. 